\title{
Discussion on the Feasible Path of Intelligent Community Participatory Governance in New Media Context
}

\author{
Honglu Fan \\ School of Culture and Social Development Studies \\ Southwest University \\ Beibei, Chongqing, China \\ fanhonglu5117@163.com
}

\author{
Tangbo Li \\ Journalism School \\ Yunnan University \\ Kunming, Yunnan, China \\ ltb-mc2011@hotmail.com
}

\begin{abstract}
The focus of this paper was the involvement of new media in community governance with the aim to construct intelligent community and achieve community participatory governance. Combining communication and sociology, this paper was based on agenda-setting and cultivation analysis and started from the perspective of mass communication, which was a new and original research view. By using literature research and analytical method, the specific path was presented as follows: by taking advantage of new media's feature, the government could innovate participatory ways, enhance community members' awareness of participation and strengthen the platform supervision. The market could support the platform's good operation through the government purchase of services. Citizens could actively participate in community governance so as to build a harmonious community.
\end{abstract}

Keywords—new media; intelligent community; agenda-setting; cultivation analysis; participatory governance

\section{INTRODUCTION}

Community governance has become a major concern in future development of China. Current society is a risky, developmental and administrative society. "Resolving social contradictions in risky society needs citizen participation, meeting high demand of people in developmental society relies on citizen participation, improving management structure in administrative society depends on the citizen participation" [1]. In short, citizen participation has become an inseparable focus of social governance. In September 2015, the State Council issued "Action Plan for Promoting the Development of Big Data”, which clearly put forward to construct a new social governance model of precise management and multi-subject cooperation in the next 5 to 10 years [2].This provided an opportunity for new media to get involved in community participatory governance.

\section{LITERATURE REVIEW}

Ostrom put forward multi-center governance theory and emphasized the diversity of the public service supply structure and the interactive relationship [3]. J. Kooiman thought cooperative governance was a mode that public power and demotic power participated in public affairs management, and it was a network management system composed of modern government and social forces through face to face cooperation [4]. Corinne Damlamian explored community governance starting from the relationship among government, enterprises and non-governmental organizations[5]. B. Guy Peters and Ostrom proposed the marketization of community governance and thought marketization governance could expand citizens' option rights [3,6]. Xiaoping Jiang, Xia Heng and Xiaoli Xia thought citizen participation was the essence of community governance and the core of China's political construction of democracy at basic level, which was beneficial for enhancing the sense of belonging and identity of citizens [7, 8]. The above researches have explained the feasibility and advantage of participatory governance, which provides a theoretical support for community participatory governance.

In the face of emerging new media, scholars believed that new media shortened the delay of agenda-setting effect, and audience agenda would influence media agenda [9]. The new form of agenda-setting theory in new media context was agenda integration. Professor Dan Huang in Fudan University thought people could use this to develop social relations, form new social groups and maintain the community [10]. Therefore, constructing an intelligent community via using agenda-setting and cultivation analysis of new media to achieve community participatory governance was an innovation on the basis of existing research.

Through the literature review, we know that now for community governance, research has made some achievements, but there is almost no research using new media to develop community participatory governance from the perspective of agenda-setting and cultivation analysis of the mass media. Accordingly, we hope that from the perspective of mass communication and through using new media to construct the intelligent community and promote citizen participation in community, the advantage of participatory governance can be exerted so as to bring social governance of multiple subjects into practice and implement community governance. 
III. The FEASIBILITy ANALYSIS OF NEW MEDIA PARTICIPATING

\section{IN COMMUNITY GOVERNANCE FROM THE PERSPECTIVE OF \\ MASS COMMUNICATION}

If new media can integrate into the community governance, there must be some utility or effectiveness. We have compared well-done intelligent community in Peking, Guangzhou, Hangzhou, etc., and have summed up some feasible supports as follows.

\section{A. The Convenience of Communication Platform}

The new media (especially the "user-operated media") , as new forms of mass communication, make agenda-setting form of traditional mass communication diversified. Audiences can join the agenda-setting, and various ways of suggestion expression and communication are increasing, which makes the spread and reception of information become fast and convenient and ensures the information is fresh and timely. It is beneficial for community information to be open, transparent and unimpeded. At the same time, the convenience of new media will help to expand new media's coverage. The application of new media in community governance is also important to the information transmission of emergency in the community.

\section{B. The Diversity of Spreading-Receiving Relationship}

Under the background of network communication decentralization, the agenda-setting subjects become diversified. The public can set the agenda as well. They have relatively free rights to talk, and the spreading-receiving relationship is changed. Every audience may become a reporter via new media. A scholar said: “user-generated content (UGC) broke the monopoly and privilege of traditional media in news spread and made the media source structure change.” [11] Using new media in community governance can make the community self-government organizations and the members have equal and effective communication so as to better deal with the problems in the process of community governance.

\section{The Timeliness of Information Feedback}

The interaction of new media can achieve audiences' independent choice and information feedback. Taking advantage of the new media's feature that information feedback is timely and effective can improve the efficiency of community governance. Collecting the opinions and suggestions from community members in time and hearing the voice of the public can reduce community contradiction, improve the efficiency of community governance, promote community self-improvement and stimulate the construction of harmonious community. Meanwhile, it is also beneficial to the mutual communication among the community members. It can enhance the cohesion of the community.

\section{The Obviousness of Communication Effect}

In aspect of exerting agenda-setting function of mass media, new media publish information via micro-blog, WeChat, BBS, etc. to lead audiences' perception, and then highlight the issues by establishing topics, setting headlines and so on. Moreover, information sorting can be used to influence audiences' judgment and lead the focus that audiences pay attention to. Therefore, in community governance, using new media can mobilize community members' enthusiasm of participation in community governance, promote community members to exert subjective initiative and form their value identity and sense of belonging. Thus it can strengthen community unity and enhance community cohesion.

\section{E. The Universality of Social Influence}

The total amount and the flow rate of information in the network have gone through a geometric leap. There are more and more events which were widely concerned in the society via new media. For instance, micro-blog launched in an "Ice Bucket Challenge”, which attracted public attention and care for the children with amyotrophic lateral sclerosis. New media have widespread audiences, which can have extensive social influence in community governance and exert the new media's function in agenda-setting. In addition, due to the widespread use of new media, there will be some "opinion leaders", such as the "Weibo (micro-blog) VIP". They may be the main strength to influence public opinion, which is also helpful to the expression of public opinion in community.

\section{THE PATH CONSTRUCTION OF PARTICIPATORY INTELLIGENT \\ COMMUNITY IN NEW MEDIA CONTEXT}

Combined with new media's advantages and characteristics and based on the feasible analysis of new media participating in community governance, we can innovate participation ways through government, cultivate citizens' awareness of participation in community affairs via agendasetting, and strengthen the platform supervision to provide conditions and guarantees for new media involved in community participatory governance. Meanwhile, in aspect of the market, professional technical support and service platform can be provided for intelligent community through government purchase of services. Moreover, regarding citizens, they, as community members, need to enhance their consciousness of citizen and actively participate in community governance so as to promote the formation and cohesion of social capital. Thereby, through agenda-setting, multi-linkage mechanism of participatory governance in intelligent community can be formed so as to construct feasible path of intelligent community participatory governance in new media context (Fig. 1.).

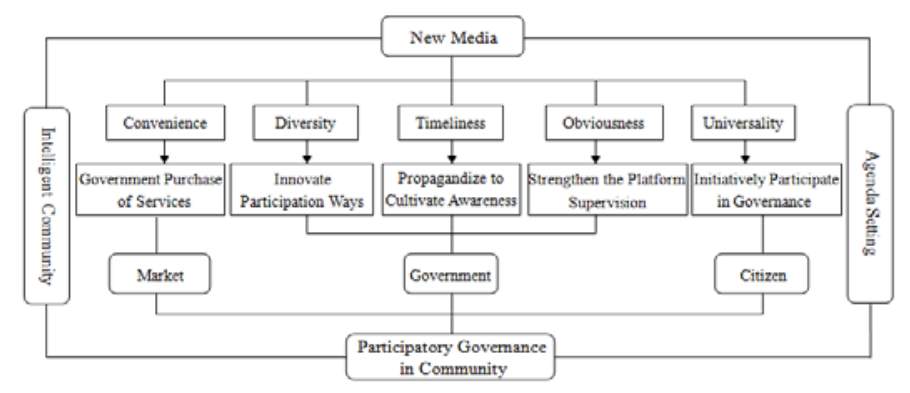

Fig. 1. Logic framework of constructing intelligent community via new media to promote participatory governance 


\section{A. Construct New and Intelligent Informatization Platform and Innovate Participatory Governance Ways}

Firstly, construct social management system of intelligent community. It is a comprehensive information application platform that integrates relevant subjects of participatory governance. It can also integrate relative departments' work records, inspection reports, community profiles, asset management and other information, forming a set of basic data base to achieve information sharing and intelligent interaction among subjects.

Secondly, construct internal management system of intelligent community. It can use big data and cloud computing to collect and store basic data of area residents, migrant population, organizations, residents' housing and so on, then becomes a database information system, which is convenient for efficient management in community.

Thirdly, construct public service system of intelligent community. This system achieves intelligent public service and avoids community "fragmentation" management by integrating information about transportation, medical care, education, and environment and so on. It can realize online community service and residents can deal with affairs online as well. At the same time, "Volunteer Help" section can be added to the system.

Fourthly, construct information exchange system of intelligent community. It can be divided into the following three sections: "community news", "community forums" and “community bulletin”.

These four subsystems provide a platform for the construction of intelligent community, in which the agendasetting subject of the social management system and the internal management system is mainly the authority. The other two systems reflect the interaction between the public and the government, and the agenda-setting subject of them can be community members. The whole system constitutes the foundation and prerequisite of the existence of intelligent community.

\section{B. Use the Propaganda Function of New Media and Enhance Community Members' Awareness of Participation}

New media, compared with traditional media, show many characteristics which make it to have more and deeper impact on the audience. However, the core of participatory governance in community through agenda-settings lies at the change of people's attitudes and behavior. Therefore, letting people participate in community governance and exerting the subjectivity of community members will make great achievements on community governance. New media provide a good information exchange platform for the real-time interaction among people. There is no doubt that the platform's convenience of information sharing and communication can achieve the "group consensus", build relationships among social members and eliminate the phenomenon of group polarization [12]. Thus, a variety of communication channels should be set up.

Firstly, propagandize relative information about community construction. Secondly, through people's interaction via new media, increase contact among community members and enhance their sense of belonging and community cohesion. Use new media to build interpersonal relationship network in the community and develop the social capital of community members. Efficiently handle community affairs through the strong tie and weak tie among members. Meanwhile, through the use of new media, form informal organization that is beneficial to the community construction and development. Actively communicate with "opinion leaders" in informal organization, promote harmonious neighborhood relationships, and strive to make "stranger society" obtain the benefits and happiness of "acquaintance society”.

\section{Strengthen the Platform Operation Supervision and Protect the Intelligent Community Construction}

The government should strengthen the management of information and virtual organization in the platform of intelligent community. On the one hand, the government should guide and strengthen information publishers' social responsibility awareness and the information content management, be a good and responsible "gatekeeper" and ensure that the system runs smoothly through publishing a series of policies and regulations that promote intelligent community construction. The State Administration of Press, Publication, Radio, Film and Television introduced "Notice about Strengthening Journalists' Network Action Management” in 2013, putting forward to further standardize the news collection and edit behavior and further strengthen the management of media news sites, blogs and microblogs[13], which could provide a safe and healthy environment for the agenda-setting of the new media.

On the other hand, the government should strengthen contact and communication with the basic-level community, increase interaction, promote cooperation, pay attention to hot news and have real-time monitoring to social public opinion. In addition, if the government or the community committee meets emergencies that influence public lives or social order, they are supposed to tell the truth to the public by new media in time, guide public opinion correctly, avoid rumors spread and avert "spiral of silence" so as to stabilize social order. At the same time, the government can use new media to manage crisis, maintain the reputation and public trust and build a good image.

\section{Use Government Purchase of Services and Support the Platform's Good Operation}

The intelligent community information platform has many advantages, but in aspect of practice, there are some constraints. Some scholars have pointed out that the realization of intelligent community follows the path that business factors are grafted after the basic facilities are improved. But there is often a shortage of funds. Therefore, the intelligent community always deters the government due to its expensive investment and high risk.

Hence, letting the valuable community intelligence platform play its positive role requires the government to give strong support so as to prevent nontechnical factors from 
becoming an obstacle to the use of the platform and the convenience of people's livelihood. Zhejiang intelligent community network which Jinliang Wu surveyed gave us a feasible and effective way to refer. He believed that the government should take the way that the third party supported and paid for the user (all kinds of users in community) [14], which meant the company was responsible for investment, maintenance, system upgrades and other work. Through the purchase of services, the government pays for the users and the users (the community) need to pay the necessary service fee to the company on a monthly basis or on an annual basis. Here, although the government does not need to develop the information platform directly, but it must undertake the task of evaluation and supervision to the platform. Thus, the government can effectively play its own role and ensure good effect of agenda-setting and cultivation.

\section{E. Exert People's Initiative of Participation in Governance and Promote the Development of Harmonious Community}

Community participatory governance needs individuals, community organizations, government, etc. to cooperate. Therefore, as one of the important subjects of community participatory governance, community members should actively participate in the process of community governance and exert their subjective initiative. Through the intelligent community platform, community members ought to concern about the community, enhance their sense of community integration and belonging, play their roles as community hosts and contribute to the community governance.

Community members can take advantage of the characteristics of new media, such as interactivity and convenience, to cultivate their consciousness of citizenship. By becoming one of the agenda-setting subjects, community members should actively build community interpersonal network and integrate into the community to promote timely communication among community members, community organizations and the government. They need to handle suggestions transmission and information feedback well, grasp the advantage of participatory governance, make community members exert their initiative of participation in community governance, enhance mutual trust and cooperation and bring into play the positive effect of social capital in the intelligent community construction, so that the development of community governance and the construction of harmonious intelligent community can be promoted.

\section{Conclusion}

With the rapid development of information technology in the modern times, the influence of new media on public lives has become more and more profound. After "smart city" has become an innovative path of social construction and social development, the concept of "intelligence community" has gradually attracted social attention. Community is a crucial part of society, and the key of social governance is community governance. The intelligent community focuses on information development, intelligent development and humanism development of the community, promotes community members and community organizations to participate in community governance and exerts the positive effect of participatory governance via new media so as to promote the development of the community and society. Constructing intelligent community is an innovative way of community governance in the new media era. New media exert agenda-setting and cultivation function of mass media in community governance, which can mobilize community members' enthusiasm of participation in community governance, promote communication and cooperation among community members, promote the formation and cohesion of social capital, promote community construction and development, and ultimately achieve effective community governance and social harmonious development.

\section{REFERENCES}

[1] W. T. Chen, "Improve the way of social governance: exert the basic role of public participation," Journal of the Party School of CPC Jinan Municipal Committee, vol. 1, pp. 75-78, 2014.

[2] Editor, "Use big data to create a new model of social governance," Zhejiang Daily, vol. 5, 2015.

[3] Ostrom, “Crowding out citizenship, ” Scandinavian Political Studies, vol. 23, pp. 3-16, 2000.

[4] J. Kooiman, “Social-political governance, ” Public Management Review, vol. 1, pp. 67-92, 1999.

[5] C. Damlamian, "Corporate-NGO partnerships for sustainable development,” College Undergraduate Research Electronic Journal, pp. 1-48, May 2006.

[6] B. Guy Peters, "The future of governing four emerging models,” Beijing China Renmin University Press, 2013.

[7] X. P. Jiang and X. Heng, "Citizen participation in community governance,” Hunan Social Scineces, vol. 1, pp. 24-28, 2007.

[8] X. L. Xia, "Citizen participation, urban community governance and democratic values,” Chongqing Social Sciences, vol. 2, pp. 38-45, 2014.

[9] Z. B. Jiang and R. Y. Deng, "Analysis on the development of foreign agenda-setting research in new media environment," Journal of International Communication, vol. 6, pp. 39-45, 2010.

[10] X. F. Chao, "Research on agenda-setting theory development in the new media era,” China Newspaper Industry, vol. 2, pp. 78-79, 2014.

[11] C. X. Huang, "Journalism communication education innovation under the background of media integration,” Contemporary Communications, vol. 6, pp. 93-94, 2010.

[12] G. M. Yu, “The influence of Weibo,” PR Magazine, vol. 3, pp. 46-51, 2010.

[13] Xinhua Net, “The State Administration of Press, Publication, Radio, Film and Television will strengthen journalists' network activities management,"http://news.xinhuanet.com/legal/201304/16/c_124588101.htm, 2013-04-16.

[14] J. L. Wu, “Use 'intelligence revolution’ to promote China's basic-level community reconstruction -- analysis on community construction value of Zhejiang intelligent community network," Journal of Zhejiang Provincial Party School, vol. 28, pp. 37-44, 2012.

[15] M. E. McCombs, D. L. Shaw, "The agenda-setting function of mass media,” Public Opinion Quarterly, vol. 36, pp. 176-187, 1972.

[16] H. S. Zheng and J. L. Huang, "The new trend of current social management and community governance in China," Gansu Social Sciences, vol. 6, pp. 1-8, 2012.

[17] Y. G. Shi and H. M. Tu, "Basic-level social cooperation governance: perfect the Chinese characteristics,” Social Science Research, vol. 3, pp. 48-54, 2010. 